\title{
Lessons Learned from the COVID-19 Pandemic
}

\author{
Alfonso Fuggetta
}

\begin{abstract}
The COVID-19 pandemic is having a tragic and profound impact on our planet. Thousands of lives have been lost, millions of jobs have been destroyed, and the life of billions of people has been changed and disrupted. In this dramatic turmoil, digital technologies have been playing an essential role. The Internet and all its services have enabled our societies to keep working and operating; social networks have provided valuable channels to disseminate information and kept people connected despite lockdowns and the block of most travels; most importantly, digital technologies are key to support researchers, epidemiologists, and public officers in studying, monitoring, controlling, and managing this unprecedented emergency.

After more than a year, it is possible and worthwhile to propose some reflections on the strengths and weaknesses we have experienced and, most importantly, on the lessons learned that must drive our future policies and roadmaps. This is unavoidable not just to improve our ability to react to these dramatic situation, but, most importantly, to proactively design and develop a better future for our society.
\end{abstract}

\section{Lesson 1: Increase Digitalization}

At the beginning of March 2020, as many other countries, all of Italy was put on lockdown: stores and schools were closed, most workers started working remotely, industries were forced to operate with limited staff, and traveling was basically cancelled. The key infrastructure that kept the country alive and operating was the Internet. Nevertheless, there were (and still are) problems that could not be solved instantaneously: significant portions of the territory do not have adequate network access and services; most public administrations do not manage all the information digitally and, most important, operate as separate silos that do not exchange and integrate their data and processes; too many companies were unprepared to work as

\footnotetext{
A. Fuggetta $(\bowtie)$

Cefriel - Politecnico di Milano, Milan, Italy

e-mail: alfonso.fuggetta@cefriel.com 
an agile and decentralized organization and to implement smart-working policies and procedures; and the health system was overwhelmed and had to deal with a sort of war-time emergency. The key problem was the lack of preparation: we didn't plan, and we didn't organize our society to deal with these kinds of events. We just reacted, and reaction cannot instantaneously fix problems and issues of such magnitude.

This was not just Italy's problem. All countries have been struck and caught by surprise. The first lesson we should learn from this emergency is that optical fibers cannot be laid down "on demand," processes cannot be set up "when needed," the society cannot adapt "by decree," and people and companies cannot just "react": we need to anticipate and shape the future rather than just dealing with it when emergencies occur.

\section{Lesson 2: Speed Is More Important Than Money}

When the crisis erupted, Italy was unable to procure all the masks needed to deal with the emergency. It was not a matter of a lack of resources: there were no production and sourcing capabilities, and it took weeks and months to create them. A country with a very high GDP, a member of the G20, was unable to procure basic devices such as masks. Similarly, when Italy decided to launch a contact tracing app, the real issue was not the cost of developing the app or integrating it with the national health information system: the real issue was the time needed to put it into operation. As an additional example, the same problem occurred to define and deploy an interoperability strategy for the different COVID-19 apps developed in Europe.

In an emergency, the critical resource is time, not money. Consequently, the speed and efficiency of processes are of paramount importance. It depends on the level of preparedness (as discussed in the previous point) and on the efficiency and clarity of the command chain within the different branches of the government and of the society in general.

Time cannot be procured.

\section{Lesson 3: We Need to Find a New Balance Between Privacy and Public Good}

The need to trace and control the pandemic has generated a heated and turbulent discussion about a crucial and sensitive issue: privacy preservation. Indeed, the characteristics of the virus do require the availability of fast and pervasive mechanisms to identify infected people that must be isolated so that the infection is blocked as soon as possible. This process can be enabled and accelerated by digital technologies and processes that trace and exploit a number of personal data and information. 
In this respect, we have seen different approaches that have explored the entire spectrum of possibilities, from light access to a minimum of personal data to a pervasive and intrusive penetration into the private lives of citizens. Too often, the debate on this topic has been unable to strike a reasonable balance between these different tensions nor to instill enough trust in the public opinion.

We need new rules, policies, and mechanisms that are able to find the appropriate balance and trade-off between promotion of societal interests and protection of freedom and civil rights. This has to be achieved by exploiting two key directions. First, as indicated by the EU Digital Services Act and related legislative initiatives, ${ }^{1}$ it is vital to provide transparent mechanisms to inform citizens about the policies and rules used to collect and use their personal data and to protect their rights and privacy. Second, it is crucial and urgent to increase our investments in education to ensure that every European citizen uses digital technologies in an informed and knowledgeable way.

\section{Lesson 4: Interoperability Is Vital}

In Italy as well as across European countries, one of the most critical problems has been the integration of different information and data sources that were key to monitor and control the pandemic. Two are the main problems:

1. Technical interoperability standards and enabling infrastructures

2. Common data schema and semantic models to interpret and exploit data coherently and effectively

Addressing these issues requires an incredible effort, similar in nature-but more challenging as far as its scope and complexity are concerned-to the creation of the GSM standard and related infrastructure. In Europe, there are two important initiatives that are trying to tackle these challenges: the Gaia-X project ${ }^{2}$ and the International Data Spaces Association (IDSA). ${ }^{3}$ The former aims at defining a European industrial and market strategy to promote and exploit cloud computing and related services; the latter aims at creating exchange standards for critical data assets.

As for the development of GSM, the Internet, and other digital technologies, standardization is an essential and crucial foundation to promote innovation, growth, and societal impact. The key concept here is coopetition: it is vital to cooperate in the creation of standards and common enabling infrastructures that define a levelplaying field while competing to offer the best services to citizens and companies based on the availability of these enabling assets.

\footnotetext{
${ }^{1}$ Directorate-General CONNECT of the European Commission. “The Digital Services Act." https:// digital-strategy.ec.europa.eu/en/policies/digital-services-act-package

${ }^{2}$ https://www.data-infrastructure.eu/

${ }^{3}$ https://internationaldataspaces.org/
} 


\section{Lesson 5: Half the Number of Words, Double the Quality of Communication}

One of the major failures that we have experienced in this pandemic is the inability to provide clear and convincing messages to citizens. Such an incredible crisis would have demanded for an evidence-based communication strategy that too often has been completely absent or insufficient. Even worse, we have been overwhelmed by an unmanageable amount of incoherent, confusing, and often contradicting messages.

Government, companies (e.g., big pharma), and scientific institutions need to raise the bar in their communication strategies and practices, to provide the public with appropriate and trustworthy information on the evolution and management of the emergency. This has to be achieved by combining clear and coordinated communication strategies and procedures (especially as far as public bodies are concerned) with a streamlined, timely, and coherent exploitation of digital media and social network.

\section{Lesson 6: Competences Are the Priority}

Managing complexity demands for a substantial improvement of our competences as public officers, researchers, educators, and citizens. We cannot manage such a challenging crisis if we do not have the cultural and scientific means that can help us understand and deal with it. Of course, different roles would require different levels of knowledge and expertise. However, as a society, we need to elevate the average level of education and competence of each citizen. This requires a coordinated set of actions:

1. Provide digital awareness courses at all levels of the education system and with a lifelong learning vision.

2. Rethink and reimagine all curricula and disciplines to keep into account how digital technologies have dramatically changed them (e.g., geography and math).

3. Provide support and guidance to our students in the selection of their studies and careers so that we can increase the number of professionals in STEM.

4. Establish or strengthen curricula that bring together technology and humanities.

5. Fight school drop-out and ensure good levels of education for every citizen. 


\section{Lesson 7: Digital Technologies and Infrastructures Are Key European Security Affairs}

Apple and Google played a key role in the development of contact tracing apps. Even if - unfortunately - they didn't have a significant and wide impact on the containment of the epidemic, as Europeans, we have been basically dependent on the decisions and strategies of foreign industries. Similarly, our working and social activities heavily rely on technologies developed by American and Asian companies. It would be silly to simple promote a simplistic and unfeasible technological protectionism. At the same time, as the handling of the vaccine production and procurement processes has demonstrated, the European Union needs to define a strategy that considers science and high-tech policy a strategic and security affair, and not just a cultural or economic issue.

Open Access This chapter is licensed under the terms of the Creative Commons Attribution 4.0 International License (http://creativecommons.org/licenses/by/4.0/), which permits use, sharing, adaptation, distribution and reproduction in any medium or format, as long as you give appropriate credit to the original author(s) and the source, provide a link to the Creative Commons license and indicate if changes were made.

The images or other third party material in this chapter are included in the chapter's Creative Commons license, unless indicated otherwise in a credit line to the material. If material is not included in the chapter's Creative Commons license and your intended use is not permitted by statutory regulation or exceeds the permitted use, you will need to obtain permission directly from the copyright holder.

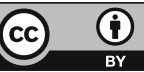

